\title{
Preface 1976
}

IN preparing this new edition of Clinton Rossiter's classic study I have not found it necessary to rewrite the original text or to change the substance of his argument. Both form and argument are beyond improvement. The Supreme Court and the Commander in Chief is durable: it is durable in the elegance of the author's style, his careful historical analysis, and his insightful interpretation of constitutional development. It is sound history which embraces an essentially sound thesis. Thus, the corpus of the original work remains intact with the exception of a few bracketed insertions to orient the reader to the year of writing; and where, in a few instances, such phrases as "the recent war" or "the recent conflict" have been changed to "World War II."

In accord with Rossiter's plan to "examine the decisions of the Court as they have followed one another in history" (page 13) I have added an Introductory Note and, in Part III, "The Constitution and the Commander in Chief after 1950," an analysis of some events which even Clinton Rossiter, with all of his prescience, could not have fully foreseen. The new material, while not intended to comprehend all constitutional developments regarding the commander in chief since 1950, is designed to point up some significant changes which I believe a quarter of a 
PREFACE 1976

century has brought light. It describes some events which have had an effect on our constitutional evolution, but particularly the impact of the broadening sweep of presidential prerogative.

Where there is error of interpretation or fact $\mathrm{I}$ am, of course, solely responsible. But where there is merit and insight I owe a profound debt to my mentor, the original author. More immediately, I am indebted to my colleagues Douglas S. Hobbs and Robert S. Gerstein, who had the uncommon experience of reviewing earlier drafts when facts and ideas were in disarray and tried their best to set me right. And I will always be deeply grateful to my wife, Mollie, who is so important in confirming that beyond the capriciousness of words there is something of value.

Los Angeles, California

Richard P. Longaker

May 1976 